\title{
Investigating How Students Transfer a Source Text into Speech through Lesson Study
}

\author{
Ilknur Bayram, (Head of Academic Affairs) \\ Cisem Altug, (Academic English Program Coordinator) \\ Firdevs Pelin Dereli, (Instructor) \\ Gokhan Yildiz, (Testing Unit Coordinator) \\ Yakup Uzun, (Instructor) \\ University of Turkish Aeronautical Association, \\ Department of Foreign Languages, Turkey
}

Doi: 10.19044/esj.2017.v13n32p49 URL:http://dx.doi.org/10.19044/esj.2017.v13n32p49

\begin{abstract}
This study was designed to explore how students enrolled at the English Academic Presentation Skills and English for Logistics Courses transfer a piece of written text into speech. Designed as a Lesson Study Project, this study was carried out during the 2016-17 Fall Semester by five teachers with the participation of 68 students from three different departments and four different classes. Data in this qualitative case study was gathered through four research lessons, classroom observations, student interviews and analysis of student work. Findings of the study revealed that students tend to make changes in a written text in five different ways to be able to present it orally. These changes fall under the headings of organizational changes, sentence level changes, summarizing the text, using key details and use of transitions.
\end{abstract}

Keywords: Lesson Study, Academic Presentation Skills, Qualitative Case Study

\section{Introduction}

Whether English teachers should or could teach academic skills which can be transferred from English for Academic Purposes (EAP) courses to other university subjects has been a hotly debated issue (Currie, 1999). Although there has been a considerable amount of study in terms of EAP courses focusing on reading and writing skills, research about EAP speaking courses is rare (Bankowski, 2010). Academic presentations have been an indispensable part of most EAP courses; however, what students do while they work with written sources before they turn them into a text to be used in their 
speech has not been researched before. Studies on paraphrasing also seem to focus mostly on how to integrate a source text into writing (Hirvela and Du, 2013; Keck, 2006; Moore, 1997). Although research of such kind may offer us insights into problems that students face while paraphrasing, more studies need to done on how students perceive paraphrasing when it comes to speaking.

This study emerged from the experiences and discussions of teachers who have been involved in designing EAP courses, teaching them in class and evaluating them during the term. One common problem teachers are occasionally confronted with is that students are inclined to memorize their speech, which mostly results in ineffective presentations. Upon recognizing that student perspective has never been taken into account while discussing how students should get prepared for academic presentations requiring basic research skills, it was decided to analyze what students tend to do first, before attempting to tackle the memorization issue that creates problems during presentations.

\section{Statement of the Problem}

In Turkey, tertiary level students whose medium of instruction is English have to take EAP courses during their first and second year at university. At the University of Turkish Aeronautical Association, Department of Foreign Languages (UTAA, DFL), such courses as Academic Presentation Skills are offered to the freshman and sophomore students so that they could practice oral communication skills toward a specified audience, study organization of ideas, the informative process and audience analysis. Those courses offered at UTAA, DFL are also designed to provide strategies to help students improve their formal oral presentation skills. As a requirement of those courses, students have to give at least one five-minute academic presentation in the classroom in front of their classmates. This presentation should ideally be based on prior research and study. However, teachers offering those courses usually complain about students trying to memorize a source text and therefore failing to present properly in front of an audience. Although being repeatedly encouraged to shorten their speech by diving it into comprehensible chunks and paraphrase it using their own words, students tend to memorize the source text word by word which leads to deficiencies in pronunciation, fluency, understanding of the subject matter and use of body language. This might be attributed to rote learning, a common problem in the Turkish education context.

Teachers offering those courses know from experience that most of the students go through the following process to complete a presentation assignment; first they decide on a topic of their interest. Then they google it. They copy all the information from a random website they google and they 
compose the source text. Once making sure that the text is long enough for them to speak for three to five minutes, they learn it by heart to be able to recite it without thinking. Teachers are in the opinion that for students to be able to deliver better presentations, they should be less dependent on the source text which necessitates raising students' awareness about how they should integrate the information that they gather from a certain source into speech.

\section{Purpose of the Study}

This study aims to explore how students transfer the source text into speech. Teachers carrying out this study recognized that the curriculum for Academic Presentation Skills assumes that students already know that they should transfer the information from a written source into oral speech, and they are also aware of how to do this. However, it is obvious that most of the students think that memorizing the source text is enough for getting prepared for a presentation. For this reason, this study is primarily concerned with understanding what students do with the text before they present it. By studying what processes students go through while they are turning a source text into speech, this study aims not only to raise students' awareness but also to help them learn from each other, thereby facilitating meaningful learning instead of rote learning and increasing teacher knowledge about understanding students so that they can deal with the issue pedagogically.

\section{Research Question}

The main question guiding the study was "How do freshman and sophomore students enrolled at Academic Presentation Skills courses transfer a source text into speech?"

\section{Methodology}

Design

Since little was known about the research question (Hancock and Algozzine, 2006), the study was designed as a qualitative multiple-case study through which an empirical investigation of a contemporary phenomenon within its natural context using multiple sources of evidence was conducted (Yin, 2014). The cases were chosen purposefully so that they could be as information-rich as possible (Patton, 2015) and so that we could learn or understand the central phenomenon (Creswell, 2013). Each case in our multiple-case study was carefully selected so that it predicted similar results (literal replication) (Yin, 2014). While deciding on the number of cases deemed necessary for the study, an important consideration was the number of teachers who was going to carry out the study. Since the study was conducted by four teachers, four case classrooms were selected. 


\section{Participants and Setting}

The study was carried out at UTAA, DFL. A foundation university established by the Turkish Aeronautical Association in 2011, UTAA specializes in aviation and astronautics. With its Faculties of Aeronautics and Astronautics, Air Transportation, Business Administration and Engineering, the school aims to educate its students to be employed in the different sectors of aviation. DFL offers English language instruction to undergraduate and graduate students through English Preparatory and Academic English Programs.

The study was conducted in four different classes in a four-and-a-halfmonth period. 68 students from the Departments of Flight Training, Aeronautical Engineering and Logistics took part in the study. 49 students were in their freshman year at university taking the Academic Presentation Skills course at the time of the study and 19 students were sophomores who had taken Academic Presentation Skills course before.

\section{Instrument}

The data for this research was mainly collected through research lessons ${ }^{1}(\mathrm{RL})$. During RLs, extensive classroom observations were made by three observers, lessons were video recorded, student discussions were audio recorded and student work completed during RLs was collected. In addition to this, one to one interviews were conducted with students chosen from varying performance levels after each RL.

The main data collection tool in the study was RLs. During this study, four RLs were implemented in four different classes. Detailed information about each RL can be found in Table 1.

As shown in Table 1, a total of nearly six hours of RLs was implemented in four different classes with the participation of 68 students. Each RL was taught in the teachers' own classes and observed by three other teachers who worked in collaboration during the lesson study process. In addition to live observations, RLs were video recorded as well, so that they could be viewed in more detail before the analysis meetings.

\footnotetext{
${ }^{1}$ Lesson Study consists of the study or examination of teaching practice by means of research lessons which are planned, observed and then analyzed collaboratively by a group of teachers (Fernandez \& Yoshida, 2004). For more information about lesson study, see the "Procedure" section.
} 
Table 1 Research Lessons Implemented throughout the Study

\begin{tabular}{|c|c|c|c|c|c|c|}
\hline $\begin{array}{l}\text { Research } \\
\text { Lesson }\end{array}$ & Date & Duration & $\begin{array}{c}\text { Number } \\
\text { of } \\
\text { Students }\end{array}$ & Teacher & Observers & Cameraman \\
\hline 1 & 09.11 .2016 & $95 \mathrm{~min}$ & 15 & $\begin{array}{l}\text { Cisem } \\
\text { Altug }\end{array}$ & $\begin{array}{c}\text { Gokhan } \\
\text { Yildiz, } \\
\text { Firdevs Pelin } \\
\text { Dereli, Yakup } \\
\text { Uzun }\end{array}$ & \\
\hline 2 & 23.11 .2016 & $85 \mathrm{~min}$ & 16 & $\begin{array}{c}\text { Gokhan } \\
\text { Yildiz }\end{array}$ & $\begin{array}{c}\text { Cisem Altug, } \\
\text { Firdevs Pelin } \\
\text { Dereli, Yakup } \\
\text { Uzun }\end{array}$ & $\begin{array}{l}\text { Ilknur } \\
\text { Bayram }\end{array}$ \\
\hline 3 & 07.12 .2016 & $85 \mathrm{~min}$ & 18 & $\begin{array}{c}\text { Firdevs } \\
\text { Pelin } \\
\text { Dereli }\end{array}$ & $\begin{array}{c}\text { Cisem Altug, } \\
\text { Gokhan } \\
\text { Yildiz, Yakup } \\
\text { Uzun } \\
\end{array}$ & \\
\hline 4 & 20.12 .2016 & $85 \mathrm{~min}$ & 19 & $\begin{array}{l}\text { Yakup } \\
\text { Uzun }\end{array}$ & $\begin{array}{c}\text { Cisem Altug, } \\
\text { Gokhan } \\
\text { Yildiz, } \\
\text { Firdevs Pelin } \\
\text { Dereli }\end{array}$ & \\
\hline
\end{tabular}

During RLs, group discussions were also audio recorded by each observer in the classroom. The reason why audio recordings were deemed necessary was because the camera was mostly located in the corner of the classroom and this prevented us from recording group discussions closely. To be able to properly hear what was going on in each group discussion, video recordings were supported by audio recordings.

After each RL the teacher implementing the lesson collected all the student work completed during the lesson. These included all the notes students have taken during group discussions and written responses to the exercises done in class.

Teachers implementing the RLs also had one to one interviews with at least three students who participated in the RLs. 27 students in total were interviewed during four RLs, and the interviews lasted approximately 85 minutes in total. All the interviews were audio recorded with students' consent.

\section{Procedure}

The study was carried out using an approach called lesson study. In lesson study, several instructors jointly design, teach, study, and refine an individual class lesson. Throughout the process they explore student learning problems and goals, examine their teaching practices, observe how students learn, and analyze how their instruction affects student learning and thinking (Cerbin, 2011). Class lessons planned, taught, analyzed and revised during the lesson study process are called research lessons (Lewis \& Hurd, 2011). As part 
of this study, four RLs were conducted using Dudley's (2014) lesson study model shown in Figure 1.

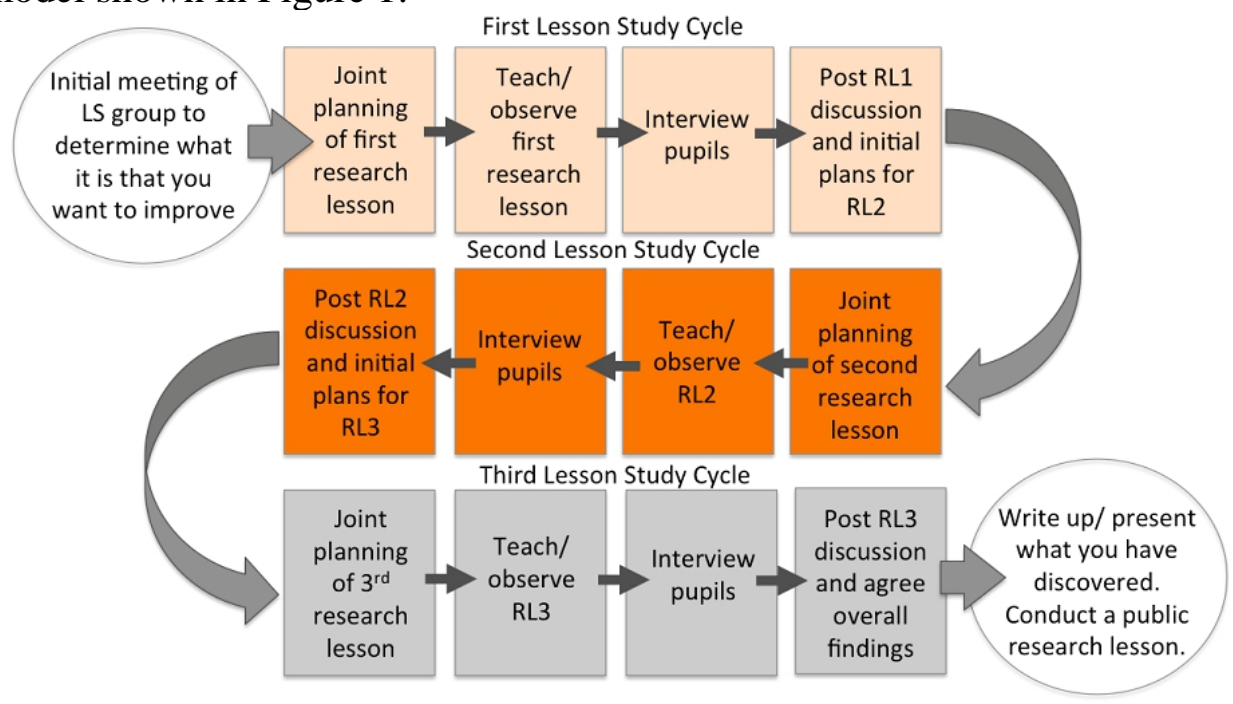

Figure 1. Dudley's Lesson Study Process

(Source: Dudley, 2014)

Lesson study is a teacher-led instructional improvement cycle in which teachers work collaboratively to formulate goals for student learning, plan a lesson, teach and/or observe the lesson, reflect on the gathered evidence, revise the lesson for improvement, and reteach the revised lesson (Lewis, 2002a). Lesson study places teachers at the center of the professional activity with their interests and a desire to better understand student learning based on their own teaching experiences (Murata, 2011). As a process in which teachers engage to learn more about effective practices that result in improved learning outcomes for students (Stepanek et al., 2007), lesson study might be considered as a good model for teachers who want to conduct research in their classes and improve their teaching.

As can be seen in Figure 1, each lesson study cycle is comprised of four stages; planning, implementation, interview, analysis and revision. To finalize the study, four lesson study cycles were completed during each of which a RL was carried out by a teacher in their own classroom. Data in the form of observations, video and audio recording and student work was collected during each RL. After RLs, students were interviewed and a debriefing and analysis meeting was held to be able to make the necessary revisions in the lesson plan before the next RL was implemented. The study was carried out during 2016-17 Fall Semester in four and a half months as shown in Table 2. 
Table 2 Phases of the Study

\begin{tabular}{cc}
\hline Week & Phase \\
\hline 1 to 6 & Planning the first research lesson \\
\hline 7 & Implementation of the first research lesson \\
\hline 8 & Analyzing the first research lesson and planning the second research lesson \\
\hline 9 & Implementation of the second research lesson \\
\hline 10 & Analyzing the second research lesson and planning the third research lesson \\
\hline 11 & Implementation of the third research lesson \\
\hline 12 & Analyzing the third research lesson and planning the fourth research lesson \\
\hline 13 & Implementation of the fourth research lesson \\
\hline 14 to 18 & Analyzing all the data and agreeing on overall findings \\
\hline
\end{tabular}

This study was carried out using lesson study for three reasons. Firstly, lesson study is known to develop teachers' pedagogical content knowledge (Fernandez, 2005). Because lesson study places student learning at its center, it helps teachers look at the content they teach from their students' perspectives. This enables them to see what misconceptions students might develop or what difficulties they encounter while trying to process a concept. In our case, we aimed at exploring students' perspectives so that we could fully understand what kinds of processes they go through when they deal with the source text before they integrate it into their speech. Secondly, lesson study enables teachers to carry out classroom-based research. In this study, four teachers who were -at the time of the study- teaching Academic Presentation Skills felt concerned about a problem area in their teaching. Therefore, they needed a model that could provide them with the opportunity to identify a research question, gather data from their students, analyze this data and make sense out of it. Lastly and most importantly, lesson study is collaborative. Doing research might be a daunting task for teachers who have to teach for nearly twenty hours in a week. In our case, all teachers who carried out this study had to teach in class and/or design courses, and/or develop tests. In such a busy schedule, teamwork seems to be a good way to handle the research process.

\section{Results and Discussion}

Data gathered throughout the study were analyzed through qualitative content analysis. By working on what things go together to form a pattern, what constitutes a theme and what to name it (Patton, 2015), coding categories were derived from the text data and results were analyzed. The study showed that students make changes in a written text under five main categories. Those categories extracted through content analysis are organizational changes, sentence level changes, summarizing the text, using key details and use of transitions. 


\section{Category 1: Organizational Changes}

Analyzing all the data obtained from each RL in the form of students' notes, video recordings, audio recordings of group discussions, and interviews, it was found out that students are mostly aware of how important it is to work on a well-organized text to succeed in their presentations.

Table 3 shows extracts from students' expressions focusing on how they made organizational changes.

During the analysis process, it was discovered that students are disposed to arrange their speech by changing the organization of the written text, which might be resulting from the organizational procedures students are expected to follow in Academic Presentation Skills Courses. Observations of RLs showed that students think they should organize the informative text they collected from the Internet so that everything would be in order and easy to follow both for students themselves and for the audience.

Table 3 Student Extracts about Organizational Changes

\begin{tabular}{cc}
$\begin{array}{c}\text { Research } \\
\text { Lessons }\end{array}$ & $\begin{array}{c}\text { Student Extracts } \\
\text { "we should put them (the paragraphs) in order" } \\
\text { "we need to organize the text" } \\
\text { "we found three main ideas" }\end{array}$ \\
\hline 1 & "let's reorganize the text" \\
"find two or three main ideas" & "we reorganized the text" \\
"we organizing the paragraphs" \\
"we will make it (the text) in order" \\
"go from general to specific"
\end{tabular}

Students that we have observed also stated that they needed to reorganize the text so that it went from general to specific. It also shows that this is another way of organizing the text to be able to make it easier for the audience to follow. To illustrate, after the $3^{\text {rd }} \mathrm{RL}$, one of the students we interviewed stated that "when we do research on our topic, we come across with some complicated and academic texts that are hard to understand, so we need to make them simple with the help of some techniques such as finding the main ideas in the text". Additionally, they applied their previous knowledge while doing the assignments given during RLs and many of the students tried to find out two or three main ideas within the text so as to split it up into two or three parts. For example, in the assessment part of $3^{\text {rd }} \mathrm{RL}$, one of the groups wrote down on their worksheet that they were going to re-organize the text, and they did so. The text distributed to students had three main parts covering three different career options in aviation (engineers, flight attendants, and pilots), but in each paragraph there were three sub-topics which were parallel 
to each other (the definition of the jobs, requirements of them, and average wages). Out of the text given, students found another set of three main ideas and they split their main body into three parts for each one of them. In the first part, they said, "we will talk about occupations in aviation", in the second part which they could not finish because of lack of time, they wrote, "we will see what they need to be in this career", and as the last main point, they stated, "we will talk about salary of each career". This group also stated that they were going to "keep it simple". By re-organizing the text, students tried to make it simple and easy to follow. Thus, the reason why students make "organizational changes" might be because it makes students' jobs much easier and simpler while they are working on their speech, and it is believed to make audiences' jobs easier while they try to follow their classmates' presentations.

\section{Category 2: Sentence Level Changes}

After a thorough analysis of the multiple types of evidence gathered from each RL, we found out a major tendency that students try to change or shorten the sentences in the written text without making a change in their original meaning. Almost in each RL, students expressed similar ideas about making sentence level changes. Table 4 presents how students stated in their own words that they should make sentence level changes in the text.

Table 4 Student Extracts about Sentence Level Changes

\begin{tabular}{c}
$\begin{array}{c}\text { Research } \\
\text { Lessons }\end{array}$ \\
\hline 11 Student Extracts \\
"we change the sentences without losing the meaning" \\
"we tried to paraphrase the sentences taken from the text" \\
"Making sentences easier to understand ..." \\
"we need cutting the sentences but the same meaning" \\
"use our sentences instead of the text on the internet" \\
"we can combine the sentences with similar meanings" \\
"we use our words, our (own) sentences" \\
"we don't need to memorize it because we choose our words and \\
sentences" \\
"we try rephrasing" \\
"we rephrased the sentences what we took" \\
"KISS - more understandable, clear" \\
"we choose simple word; our text is understandable" \\
"we shouldn't copy and paste" \\
"... use synonyms of some words" \\
"change complicated words" \\
"we simplify the sentences"
\end{tabular}

As can be seen in Table 4, to be able to change the sentences without changing the original meaning, students made use of a number of different ideas. One prominent idea was to use their own words or write their own 
sentences instead of using or memorizing the sentences in the written text. A perfect evidence for this came from a group of students in the $3^{\text {rd }} \mathrm{RL}$. In their assessment sheet, they changed the original sentence which reads as follows; "Flight attendant is an ideal career choice for someone who's interested in aviation but wants a taste of the profession with minimal educational requirements." into "if you don't want long education requirements and you are interested in aeronautics, you can choose flight attendants." Another common suggestion provided by students was to make sentences more understandable, clearer and simpler. Students generally focused on changing some complicated words with easier ones and using the synonyms of some of the words in the text. An evidence for this was found in the audio recordings of a group in the $1^{\text {st }}$ RL. "The words that you don't understand, you know, in writing the speech we just need to change the words but with the same meaning." In addition, another idea proposed by the students was to rephrase or paraphrase the sentences taken from the text. An example of this idea emerged during the $1^{\text {st }} \mathrm{RL}$. The following is an extract from what a group of four students wrote in their assessment sheet during the $1^{\text {st }}$ RL; "Everything we have to do is to paraphrase sentences without losing its meaning." It might be argued that students may have wanted to rephrase the sentences because of different reasons. One reason could be making the sentences more understandable or easier and simpler for the audience. The second reason could be to make the sentences more suitable for an oral presentation. Some students also expressed that they shouldn't copy and paste the same information from the text. In the $3^{\text {rd }} \mathrm{RL}$ we observed, a student said: "We don' $t$ need to memorize it because we choose our words and sentences. We shorter than this text. We make it shorter. Our text is not formal too much like the others. And we keep it simple. We use keywords. We add our comments about the text."

\section{Category 3: Summarizing the Text}

Results of the study showed that when preparing a speech from a text, another important part to deal with was to summarize the text as much as possible. Students referred to that with many different answers as seen in Table 5 .

It was evident in all RLs that it was important for students to come up with a shorter, simpler and more individualized text to present as a speech. Students expressed their ideas in many different ways; however, what they presented in their group work enabled us to agree on how they summarized a text. Examining the findings, it was found out that students were aware of the fact that every piece of information in a text may not be important. We can approach to this in two ways: some of them chose important points or sentences from the text to use; in other words, focused on the most important 
points; while others omitted the details or got rid of unnecessary information or sentences. The rationale behind that revealed itself in two ways: for one thing, students tried to personalize the text by using their own ideas and making some comments on some points, as they were taught in the previous lessons that the more they make personal connections with the topic, the more interesting their speech will get.

Table 5 Student Extracts about Organizational Changes

\begin{tabular}{cc}
\hline $\begin{array}{c}\text { Research } \\
\text { Lessons }\end{array}$ & Student Extracts \\
\hline 1 & "we selected important sentences" \\
"we used the most important info" & "... choose important points" \\
\hline 2 & "no copy paste but simplify and shorten the info" \\
"find the main points - important" \\
"omit the details - from specific to general" \\
"we should summarize - make it shorter" \\
"use key words" \\
"we focus on one important point" \\
\hline 3 \\
"if we use a lot of numbers, the audience will get confused" \\
"If there is extra information, it will exceed the time limit" \\
"shorten the text" \\
"writing sentences under one heading"
\end{tabular}

The second reason behind their ideas was to make what they prepare easier to present. The simpler their speech is, the more easily they can present it and also the more attention they can get from the audience. A pair of students exemplified this perfectly in the $4^{\text {th }}$ RL by telling what they have done: "After we read the text, we think that this text has so many details in it. Thus we summarize some parts and make them simply. By this way, the audience can understand easily and they can keep more attention." Therefore, students tried to shorten the text by using key words, fewer numbers and grouping related information under one heading. A good example of this was also provided in the $2^{\text {nd }}$ RL: "There are a lot of numbers. We can give an example with using this number easy way because if we say a lot of number, audience will get confused." These findings suggest that students feel the need to express the most important facts or ideas in the text they composed in a short and clear form.

\section{Category 4: Using Key Details}

Data gathered throughout all RLs suggest that students are aware of the fact that using important data such as statistical information, numbers and dates is a significant element of an effective presentation as seen in Table 6. 
Table 6 Student Extracts about Using Key Details

\begin{tabular}{cc}
\hline $\begin{array}{c}\text { Research } \\
\text { Lessons }\end{array}$ & Student Extracts \\
\hline 1 & "we used data from the text" \\
\hline 2 & "we focused on the names, numbers, words, examples" \\
\hline 3 & "data (numbersome examples and details" years ...etc) is important" \\
\hline 4 & "use key information" \\
\hline & "we should use statistics" \\
\hline
\end{tabular}

It was apparent from the observation notes and content analysis that students emphasized using statistical and numerical data in the majority of RLs. Their motive was to convey important information in the text such as numbers, names, statistics and years. In this way, they intended to get the audience's attention and prepare a more effective presentation.

Another tendency was to give as many examples as they could so that they would be able to draw the audience's attention to their presentation. A student in the $4^{\text {th }} \mathrm{RL}$ said "We try to choose some interesting informations. I mean some numbers. For example, some years." It was clearly seen from the content analysis that students in all RLs came up with the idea of using important information such as dates, numbers and years stating that they would seem more knowledgeable and this would enable them to deliver a much more interesting presentation. A good example to this can be this statement uttered by a student in the $3^{\text {rd }}$ RL: "Actually and make this presentation more interesting for listeners because we present it, I think, to our friends. They are students, too. If we make it more interesting with numbers and dates, they can focus on our topic and I think they'll like our topic and presentation. Like an empathy or something like that." Using key details appeared to be a common technique preferred by students while they prepare their speech. It could be argued that students use key details because they believe supporting their ideas with key details will help them catch the attention of the audience and make their speech more interesting.

\section{Category 5: Use of Transitions}

Just like in a typical composition, use of transitions determine the quality and flow of an oral presentation. So as to follow the presenter more easily during a presentation, it is vital to have a connection between similar ideas or different sections of the presentation. Using transitions is quite important as it enables the audience to follow the presenter and understand the points without difficulty. Table 7 shows how students referred to the use of transitions during RLs. 
Table 7 Student Extracts about Use of Transitions

\begin{tabular}{cc}
\hline Research Lessons & Student Extracts \\
\hline 1 & "combine these two sentences with a transition " \\
\hline 2 & "(we should use) more transitions like also, however, etc" \\
"make a connection between sentences" & "signposts are important" \\
"connection between the body paragraphs" \\
"We can move softly between the ideas"
\end{tabular}

Evidence accumulated throughout four RLs indicates that students did not want to move from one paragraph to another in their speech without a transition word. The main reason for using transitions was to have a better and more logical connection between the paragraphs so that their texts would be easy to follow. Here you can see an example utterance of a student from the $4^{\text {th }}$ RL: "We add some transitions like moreover, finally." Findings of this study have also shown that students had a tendency to use their previous knowledge of signposts. Therefore, we can come to the conclusion that most students know there should be transitions in a text. A good example for using transitions was provided in the $3^{\text {rd }} \mathrm{RL}$ : "Firstly, we will talk about engineers in aviation. Secondly, we are gonna talk about degree of engineers. Lastly, if you are a pilot there is something different." These findings suggest that students try to link the sentences and paragraphs in their text smoothly using transition words. This might be attributed to their previous knowledge from writing and speaking courses. It has been observed that students almost always try to go from one idea to another with the help of transitions so that their ideas will seem to be more coherently organized.

\section{Conclusion}

The findings of the study reveals two important results. The first of these results is related to the RLs conducted throughout the study. RLs have shown us that students use some techniques to integrate a source text into their speech. Those techniques mostly preferred by the students in our case study are; making changes in the overall organization of a source text, modifying the sentences in it, summarizing it, using key details and transitions. As teachers carrying out the study, we were not expecting that students would suggest or even make use of such techniques while they prepare a speech out of a source text. However, the findings of the study show that students do use those techniques before they attempt to memorize the text. This has some important implications. Firstly, if those techniques are known by teachers offering Academic Skills Courses, they can work on them with their students and try to help their students use such techniques more efficiently. If students taking those courses are made aware of such techniques or any other technique 
that their peers use to transfer a source text into speech, they may start using them as well. Therefore, this might be a solution to the memorization problem students and teachers are suffering from.

Research about paraphrasing seems to be centered around how to integrate a source text into writing. (Scollon, 1995; Setoodeh, 2015; Yamada, 2003), and the results of these studies have indicated that most of the writers copy a great deal of the source text without making use of paraphrasing techniques. As rightly suggested by Keck (2014), as teachers or researchers we tend to believe that students are inclined to copy the source text; however, this overgeneralization results in us overlooking students' use of paraphrasing strategies. This, Keck (2014) highlights, leads to unfair stereotypes about students. This study is a good example of this, showing that students do not resort to copying because it is the only thing available. They, instead, try to paraphrase but fail to do it effectively, which might be addressed by teachers pedagogically. For this reason, researchers have drawn special attention to the fact that paraphrasing strategies should be incorporated into educational programs (Shi, 2004; Roig, 2001).

The second result the study revealed is about using the lesson study model as a way to carry out classroom based research and improve teaching practices. Lesson study, as experienced by the five teachers working together in this research, is thought to be a great model not only to improve instruction but also reflect on one's teaching. This study has shown that teachers' working towards a common goal together produces better results by enabling them to see things from multiple perspectives. By receiving constructive feedback from their peers, teachers can more easily spot their weaknesses and strengths in their teaching. Therefore, teachers believe that doing lesson study might be a better alternative to one-shot workshops or seminars and to one-size-fits-all approach to continuous professional development. Lesson study is known to affect teachers' professional development in a positive way. Stigler and Hiebert (1999) highlight the importance of lesson study in terms of its influence on the professional development of teachers. Rock and Wilson (2005) state that teacher collaboration plays a key role in continuous professional development and lesson study, because of its emphasis on collaboration, is an effective model for professional development of teachers. Lewis (2002b) emphasize that lesson study help teachers deepen their subject matter knowledge mainly with the help of research lessons during which live observations are made.

\section{Suggestions for Future Research}

In this study, the strategies students use while they turn a source text into speech were explored. Another study could be designed to investigate whether students actually use the strategies they suggested. Due to time 
constraints, we could not observe students while giving real presentations. But in a more comprehensive study, students might be observed before and while they deliver a presentation in front of a real audience.

This study was carried out in four classes which makes it difficult to generalize the results. The same study might be replicated in different classes to see whether it will also produce results similar to the study we conducted.

Only three different departments from UTAA took part in this study. The same study could be carried out with students from other departments and faculties to see how this affects the findings of the study.

Lesson study proved to be an effective model in our case as a tool to use and facilitate classroom based research. More research could be done using lesson study so that our understanding of the model could be enhanced.

\section{References:}

1. Bankowski, E. (2010). Developing skills for effective academic presentations in EAP. International Journal of Teaching and Learning in Higher Education, 22 (2), 187-196.

2. Cerbin, B. (2011). Lesson study. Using classroom inquiry to improve teaching and learning in higher education. Virginia: Stylus Publishing.

3. Creswell, J. W. (2013). Educational research: planning, conducting, and evaluating quantitative and qualitative research. Boston: Pearson

4. Currie, P. (1999). Transferable skills: Promoting student research. English for Specific Purposes, 18, 329-345.

5. Dudley, P. (2014). Lesson study: A handbook. Retrieved from http://lessonstudy.co.uk/wpcontent/uploads/2012/03/new-handbookrevisedMay14.pdf

6. Fernandez, C. (2005). Lesson study: A means for elementary teachers to develop the knowledge of mathematics needed for reform-minded teaching? Mathematical thinking and learning, 7(4), 265-289.

7. Fernandez, C., and Yoshida, M. (2004) Lesson study: A Japanese approach to improving mathematics teaching and learning. New Jersey: Lawrence Erlbaum.

8. Hancock, D. R., and Algozzine, B. (2006). Doing case study research: A practical guide for beginning researchers. New York: Teachers College Press.

9. Hirvela, A., and Du, Q. (2013). 'Why am I paraphrasing?': Undergraduate ESL writers'engagement with source-based academic writing and reading. Journal of English for Academic Purposes, 12, 8798. 
10. Keck, C. (2006). The use of paraphrase in summary writing: A comparison of L1 and L2 writers. Journal of Second Language Writing, 15, 261-278.

11. Keck, C. (2014). Copying, paraphrasing, and academic writing development: A re-examination of L1 and L2 summarization practices. Journal of Second Language Writing 25, 4-22.

12. Lewis, C. (2002a). Lesson study: A handbook of teacher-led instructional change. Philadelphia: Research for Better Schools.

13. Lewis, C. (2002b). Does lesson study have a future in the United States? Journal of Social Science Education, 3 (1), 115-137.

14. Lewis, C., and Hurd, J. (2011). Lesson study step by step: How teacher learning communities improve instruction. Portsmouth: Heinemann.

15. Moore, T. (1997). From test to note: Cultural variation in summarization practices. Prospect, 12, 54-63.

16. Murata, A. (2011). Introduction: Conceptual overview of lesson study. L. C., Hart, A. Alston, and A. Murata (Ed.). Lesson study research and practice in mathematics education. New York: Springer.

17. Patton, M. Q. (2015). Qualitative research and evaluation methods. Los Angeles: SAGE.

18. Rock, T. C., ve Wilson, C. (2005). Improving teaching through lesson study. Teacher Education Quarterly, 32 (1), 77-92.

19. Scollon, R. (1995). Plagiarism and ideology: Identity in intercultural discourse Language in Society, 24, 1-28.

20. Setoodeh, K. (2015). The effect of proficiency and task type on the use of paraphrase type in writing among Iranian EFL university students. Theory and Practice in Language Studies, 5 (12), 2480-2489.

21. Stepanek, J., Appel, G., Leong, M., Turner Mangan, M., and Mitchell, M. (2007). Leading lesson study: A practical guide for teachers and facilitators. Thousand Oaks, CA: Corwin Press.

22. Stigler, J. W., and Hiebert, J. (1999). The teaching gap. Best ideas from the world's teachers for improving education in the classroom. New York: Free Press.

23. Yamada, K. (2003). What prevents ESL/EFL writers from avoiding plagiarism? Analyses of 10 North-American college websites. System, 31, 247-258.

24. Yin, R. K. (2014). Case study research: Design and methods. Los Angeles: Sage. 